\title{
Perbandingan Penggunaan Straight Line Method Dan Double Declining Balance Method Pada Aset PT. Delimas Lestari Jaya
}

\author{
Dina Satriani*1, Asep Saifudin ${ }^{2}$, Po Abas Sunarya ${ }^{3}$ \\ ${ }^{1}$ Program Studi Komputerisasi Akuntansi STTIKOM Insan Unggul, ${ }^{2,3}$ Program Studi Magister \\ Teknik Informatika Fakultas Sains dan Teknologi Universitas Raharja,

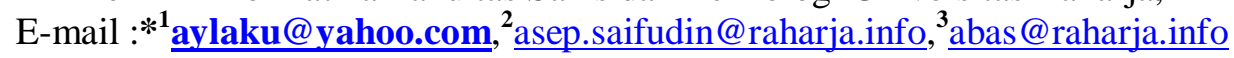

\begin{abstract}
Abstrak
PT. Delimas Lestari Jaya sebagai salah satu perusahaan yang bergerak dibidang Perdagangan Umum dan Jasa dari Kategori Konstruksi dan Real Estate.Aktiva tetap sangat berperan penting dalam kegiatan operasional sebuah perusahaan. Oleh karena itu, perlu adanya pengelolaan yang tepat terhadap aktiva tetap untuk dapat dimanfaatkan sesuai dengan kebutuhan perusahaan. menghasilkan beban penyusutan yang berbeda. Penyusutan aktiva tetap dihitung sejak bulan pengoperasian atau bulan perolehan aktiva tetap.Begitupun jika menggunakan penyusutan. Tujuan penelitian ini adalah untuk mengetahui penyusutan aktiva tetap menurut PSAK No. 16, untuk mengetahui nilai beban penyusutan aktiva tetap apabila menggunakan metode penyusutan yang lain, dan untuk mengetahui kebijakan manajemen perusahaan terhadap perlakuan aktiva tetap yang dimilikinya, serta membandingkan hasil beban penyusutan antara metode garis lurus dan metode saldo menurun.
\end{abstract}

Kata Kunci-Aktiva Tetap, PSAK No. 16, Metode Garis Lurus, Metode Saldo Menurun.

\begin{abstract}
PT. Delimas Lestari Jaya As one of the companies engaged in general trading and services of construction and Real Estate category. Assets remain instrumental in the operational activities of a company. Therefore, there needs to be appropriate management of fixed assets to be utilized according to the needs of the company. Generate different depreciation loads. Depreciation of fixed assets is calculated since the operation month or the month of fixed asset acquisition. Likewise if using depreciation. The purpose of this research is to know the depreciation of fixed assets according to PSAK No. 16, to determine the value of depreciation of fixed assets when using other depreciation methods, and to determine the company's management policy on the fixed asset treatment it has, and to compare depreciation load result between A straight line method and a declining balance method.
\end{abstract}

Keywords_Fixed Assets, PSAK 16, Straight Line Method, Declining Balance Method. 


\section{PENDAHULUAN}

Perusahaan mengakui setiap aktiva sebagai aktiva tetap jika aktiva yang dimiliki telah memenuhi sifat dan karakteristiknya, jika potensi manfaat ekonomi dirasakan dengan perusahaan dan terjadinya manfaat ekonomi aktiva jika dinilai atau di pastikan usaha akan dapat imbalan resikonya yang terkait. Biaya perolehan aktiva yang dikeluarkan bisa diukur dengan handal, bukti-bukti transaksi perolehan aktiva guna mendukung tujuan perusahaan.

PT. Delimas Lestari Jaya sebagai salah satu perusahaan yang bergerakdibidang Perdagangan Umum dan Jasa dari Kategori Konstruksi dan Real Estate. Memiliki beberapa aktiva tetap yang akan digunakan untuk membantu operasional perusahaan yang memberikan manfaat bagi perusahaan tersebut dalam jangka waktu yang relatif lama. Aktiva tetap yang dimiliki perusahaan ini adalah Kendaraan dan Alat Berat. Aktiva tetap yang dimiliki PT. Delimas Lestari Jaya memiliki karakteristik antara lain mempunyai wujud fisik, memiliki nilai yang material dimana harga aktiva tersebut cukup signifikan. Kendaraan dan Alat Berat memiliki masa manfaat ekonomi lebih dari satu tahun buku dan aktiva tersebut digunakan dalam aktifitas normal perusahaan

\subsection{RUMUSAN MASALAH}

PT.DelimasLestari Jaya masih menggunakan manual maka dari itu dibuatlah Penggunaan Straight Line Method Dan Double Declining Balance Method Pada Aset Pt. Delimas Lestari Jaya maka bisa memudahkan pekerja dalam melaksanakan tugasnya.

\subsection{LANDASAN TEORI}

\subsubsection{Aktiva Tetap}

"Digunakan dalam operasionalperusahaan tidak untuk dijual oleh perusahaan dalam bentuknormal"

\subsubsection{Penyusutan (Depresiasi)}

"Perolehan aktiva tetapbisa menjadi beban jika menggunakan cara rasional dan sistimis. Diperlukan antara pendapatan dan beban"

\subsubsection{Pengertian Faktor-faktor dalam Menentukan Biaya Depresiasi}

Memiliki tiga factor diantaranya yaitu:

a. Harga perolehan (cost)

Dana yang keluarterjadi dalam aktiva bisa di gunakan

b. Nilai sisa (residu)

Nilai aktiva adalah jumlah diterima bila aktiva dijual, ketika aktiva tidak dapat digunakan lagi.

c. Taksiran umum kegunaan (masa manfaat)

Suatu aktiva dipengaruhi kebijakan dalam reparasi. Sehingga taksiran bisa dinyatakan dalam priode waktu 


\subsubsection{Pengertian Metode Perhitungan Depresiasi}

Ada beberapa metode yang digunakan untuk menghitung penyusutan, yaitu:

a. Metode Garis Lurus (straight line method)

Besarnya beban dalam penyusutan sama setiap tahunnya, jika metode garis lurus digunakan menghitung aktiva seperti gedung, mebel, alat kantor, kendaraan dan lain-lain. Maka akan terlihat peningkatan ketelitian yang diperoleh.

Besarnya depresiasi pertahun dihitung dengan rumus sebagai berikut :

\section{Tarif $\mathbf{x}($ Biaya Perolehan-Nilai Residu $) \times$ Umur Ekonomis $=$ Akumulasi Penyusutan}

b. Metode Saldo Menurun Ganda (double declining balance method)

Perhitungan biaya depresiasi berdasarkan nilai buku asset menurun dari tahun ketahun.

Berbeda dengan metode lainnya, pada metode ini nilai residu diabaikan dalam perhitungan depresiasi tahunan. Akan tetapi, nilai residu akan menjadi batas jumlah depresiasi yang akan dilakukan. Depresiasi akan berakhir apabila nilai buku telah mencapai jumlah yang sama dengan taksiran nilai residu. Tarif depresiasi yang sering digunakan adalah tarif metode garis lurus yang dikalikan dua, sehingga metode ini sering disebut metode saldo menurun ganda (double declining balance method). Metode saldo garis lurus di atas yaitu $20 \%$ akan dikalikan 2 sehingga tarifnya menjadi $40 \%$.

Rumus dan perhitungan depresiasi pada metode ini adalah :

\section{Tarif $\mathbf{x}$ Biaya Perolehan $\mathbf{x}$ Umur Ekonomis = Nilai Buku}

\subsection{LITERATURE REVIEW}

1. Lestari, Rizky[9] menganalisis perolehan aset tetap di Dinas Perhubungan Kabupaten Bandung, dengan metode verifikatif dan desain penelitian kualitatif.Hasil perolehan aset tetap di Dinas Perhubungan Kabupaten Bandung sudah sesuai dengan Peraturan Bupati Bandung Nomor 93 Tahun 2017. Dinas Perhubungan Kabupaten Bandung telah memenuhi 3 syarat dalam menerapkan penyusutan, yaitu identitas aset yang kapasitasnya menurun, nilai yang dapat disusutkan, masa manfaat dan kapasitas aset. Metode penyusutan garis lurus lebih cocok digunakan untuk aset yang memiliki masa manfaat di atas 10 tahun dan metode saldo menurun ganda lebih cocok digunakan untuk aset yang memiliki masa manfaat di bawah 10 tahun.

2. Jayanti, Putri Okta Dwi[10] Metode penelitian yang digunakan adalah deskriptif kuantitatif. Hasilnya untuk aktiva lapangan golf perusahaan, sarana umum, dan mesin tetap menggunakan metode persentase tetap dari nilai buku atau metode yang sudah digunakan selama ini oleh perusahaan. Tetapi untuk aktiva bangunan menggunakan metode jumlah angka tahun dan untuk lapangan golf PGB, kendaraan, alatberat, mebeul, perlengkapan restoran, peralatan kantor dan aktiva lainnya menggunakan metode saldo menurun ganda sehingga laba perusahaan menjadi besar.

3. Adelia, Dhea[11] menganalisis perbandingan harga pokok produksi kain songket motif Bintang Berante dan Bunga Inten berdasarkan pesanan untuk bulan Januari 2018 pada Pengrajin Songket VR Textile dan Hj. Asmi Astari Songket. Data yang didapat oleh penulis berupa data dari hasil wawancara, dari data yang ada diperoleh nilai penggunaan bahan baku langsung, tenaga kerja langsung, dan biaya-biaya lainnya. Permasalahan yang 
ada pada Pengrajin Songket VR Textile dan Hj. Asmi Astari Songket yaitu pengrajin belum mengalokasikan biaya transportasi pembelian bahan baku, belum adanya pembebanan biaya penyusutan aset tetap dan tidak memperhitungkan alokasi biaya bersama berupa biaya listrik dalam perhitungan harga pokok produksi. Berdasarkan permasalahan yang ada, penulis menyarankan agar pengrajin dapat lebih tepat dalam mengalokasikan unsur-unsur biaya yang terlibat dalam perhitungan harga pokok produksi kain songket, sehingga dapat menentukan harga jual yang tepat dan mencapai laba yang seharusnya.

4. Linda Arisanty Razak dkk[12] Dalam menghitung penyusutan aset tetap perusahaan dapat menggunakan standar akuntansi keuangan dan peraturan perpajakan. Perbedaan beban penyusutan antara perusahaan dan perpajakan dapat menimbulkan adanya koreksi fiskal. Tujuan dari koreksi fiskal yaitu untuk menyesuaikan laba komersial dengan ketentuan perpajakan sehingga diperoleh laba fiskal. Jenis penelitian ini yaitu analisis deskriftif kiantitatif. Hasil penelitian ini menunjukkan bahwa perusahaan telah mengitung beban penyusutan sesuai dengan standar akuntansi keuangan tetapi belum melakukan perhitungan beban penyusutan berdasarkan ketentuan perpajakan. Perbedaan antara beban penyusutan menurut standar akuntansi keuangan dengan peraturan perpajakan menyebabkan terjadinya fiskal positif dimana laba komersial sebesar Rp. 61.443.212.441 sedangakan laba fiskal sebesar Rp 62.487.316.096.

5. Andini Nazar Pratiwi dkk[13] Penelitian ini bertujuan untuk memberikan gambaran bagaimana book-tax differences, leverage, dan ukuran perusahaan pada perusahaan properti dan real estae yang terdaftar di Bursa Efek Indonesia tahun 2013-2017 serta mengetahui pengaruh book-tax differences, leverage, dan ukuran perusahaan terhadap persistensi laba. Metode penelitian yang digunakan adalah metode deskriptif verifikatif. Populasi dari penelitian ini yaitu sebanyak 85 perusahaan perusahaan properti dan real estae yang listing di BEI periode 2013-2017. Metode pemilihan sampel penelitian ini menggunakan metode purposive sampling dengan total 17 perusahaan yang memenuhi kriteria. Analisis data dilakukan dengan menggunakan uji asumsi klasik dan pengujian hipotesis dengan regresi linier berganda. Berdasarkan hasil penelitian bahwa sebagian besar perusahaan perusahaan properti dan real estae yang listing di BEI tahun 2013-2017 book-tax differences termasuk dalam kategori sedang, untuk leverage termasuk dalam kategori tinggi, ukuran perusahaan termasuk dalam kategori sedang, dan persistensi laba termasuk dalam kategori tinggi. Secara parsial book-tax differences, leverage, dan ukuran perusahaan berpengaruh terhadap persistensi laba. Dan secara simultan book-tax differences, leverage, dan ukuran perusahaan berpengaruh terhadap persistensi laba Kata kunci: book-tax differences, leverage, ukuran perusahaan, dan persistensi laba.

6. Wida Khusnul Khotimah dkk[14] membangun sebuah aplikasi web yang dapat mengelola aset perusahaan. Aplikasi berbasis web ini dibangun dengan orientasi objek dengan pengembangan model Software Development Life Cycle (SDLC) serta menggunakan bahasa pemrograman PHP dan framework CI. Aplikasi ini dapat menengahi proses yang terjadi pada aset tetap perusahaan, mulai dari pembelian, penyusutan, perbaikan, serta revaluasi. Adapun laporan yang dihasilkan berupa jurnal, buku besar, laporan pembelian, dan laporan aset tetap untuk memenuhi kebutuhan informasi tentang aset dalam perusahaan. 


\section{METODE PENELITIAN}

\subsection{Objek Penelitian}

Objek penelitian penulis bertempat di PT. Delimas Lestari Jaya yang beralamatkan di Jl. Fatahillah Link. Cirubuh Desa Tegal Ratu Kecamatan Ciwandan Cilegon-Banten 42446. PT. Delimas Lestari Jaya adalah perusahaan Perdagangan Umum dan Jasa.

\subsection{Jenis Penelitian}

Jenis penelitian ini termasuk penelitian deskriptif, hal itu dikarenakan aktiva tetap berhubungan erat dengan penyusutan untuk melihat umur ekonomisnya.

\subsection{Metode Pengumpulan Data}

Dalam penyusunan proposal, penulis berusaha mendapatkan data yang benar dan akurat. Dalam mendapatkan semua data yang dibutuhkan penulis menggunakan metode-metode sebagai berikut:

\subsubsection{Pengamatan Langsung (Observasi)}

Yaitu teknik pengumpulan data dengan mengamati secara langsung objek penelitian dengan melihat kegiatan yang ada hubugannya dengan objek yang diteliti.

\subsubsection{Wawancara (Interview)}

Yaitu tanya jawab secara langsung dengan karyawan PT. Delimas Lestari Jaya. Dalam wawancara tersebut penulis melakukan konsultasi dan tanya jawab langsung dengan karyawan yang berwenang dalam perusahaan tersebut. Dari wawancara tersebut akan diperoleh data mengenai aktiva tetap yang dimiliki perusahaan, serta pendapat mereka mengenai metode penyusutan aktiva tetap dan perlakuan aktiva setelah disusutkan.

\subsubsection{Studi Pustaka}

Yaitu dengan mendatangi perpustakaan dan mencari buku-buku yang sesuai dengan masalah yang diangkat dan informasi yang didapat digunakan untuk memecahkan masalah yang berkaitan dengan metode penyusutan.

\subsection{Identifikasi Variabel}

Dalam identifikasi variabel terdapat dua variabel, yaitu:

Variabel X adalah :Analisa Aktiva Tetap.

Variabel Y adalah : Metode Penyusutan. 


\section{HASIL DAN PEMBAHASAN}

\subsection{Pelaksanaan Analisa Laporan Penyusutan Kendaraan dan Alat Berat pada PT. Delimas Lestari Jaya.}

Dalam pelaporannya penyusutan di PT. Delimas Lestari Jaya dibuat dalam daftar aktiva tetap yang masih berfungsi menurut klasifikasinya yaitu Daftar aktiva tetap yang masih berfungsi.Dimana perhitungan biaya penyusutan aktiva tetap didasarkan atas manfaat dari tiap jenis aktiva yang bersangkutan yang dihitung secara bulanan/tahunan dan pembebanannya dilakukan tiap akhir periode pembukuan.Penyusutan aktiva tetap dihitung sejak bulan pengoperasian atau bulan perolehan aktiva tetap. Langkah-langkah dalam melakukan analisis laporan daftar akiva tetap yang masih berfungsi pada kendaraan dan alat berat adalah sebagai berikut :

1. Mempelajari dan memahami laporan daftar aktiva tetap yang masih berfungsi pada kendaraan dan alat berat

2. Memahami latar belakang data aktiva tetap berupa kendaraan dan alat berat pada PT. Delimas Lestari Jaya.

3. Mempelajari dan memahami bagaimana perlakuan aktiva tetap tersebut setelah disusutkan.

4. Aktiva tetap yang ada di PT. Delimas Lestari Jaya sudah memenuhi syarat untuk disusutkan karena masa manfaatnnya lebih dari satu tahun dan dapat memberikan manfaat kepada perusahaan selama bertahun-tahun.

\subsection{Aktiva Tetap}

Aktiva tetap yang dimiliki PT. Delimas Lestari Jaya dinilai berdasarkan biaya perolehan, yaitu seluruh pengeluaran yang dikeluarkan untuk memperoleh aktiva tetap sampai dengan berada ditempat dalam kondisi siap pakai.

Nilai aktiva tetap berdasarkan perolehan adalah:

a. Aktiva tetap diperoleh melalui pembelian secara tunai dinilai dengan harga beli dan semua biaya yang dikeluarkan sampai aktiva tetap bersangkutan siap digunakan.

b. Aktiva tetap yang diperoleh melalui pertukaran dimiliki berdasarkan harga pasar yang berlaku.

c. Aktiva tetap yang diperoleh melalui cara membangun sendiri dimulai berdasarkan jumlah keseluruhan

d. Keseluruhan biaya yang diterapkan dalam rangka pembangunan aktiva tersebut hingga siap digunakan.

e. Umur ekonomis yang digunakan oleh perusahaan ialah 5 tahun. 


\subsection{Metode Garis Lurus (straight line method):}

\begin{tabular}{|c|c|c|c|c|c|c|c|c|c|c|c|c|c|}
\hline \multicolumn{14}{|c|}{$\begin{array}{l}\text { DAFTAR AKTIVA OPERASIONAL YANG MASIH BEREUNGSI } \\
\text { MILIK PT. DELIMAS LESTARI JAYA } \\
\text { METODE GARIS LURUS }\end{array}$} \\
\hline \multirow[t]{2}{*}{ No } & Nama Aktiva & Qty & Tgl Pembelian & Tgl Mulai & & Jumlah & & ai Residu & Tarif & \multicolumn{2}{|c|}{ Akum Penyu } & \multicolumn{2}{|r|}{ Nilai Buku } \\
\hline & Kendaraan dan Alat Berat Tahun 2011 & & /Pemakaian & Disusut & & ya Perolehan & & & Pertahun & & Thn ini & & Tahun ini \\
\hline \multirow[t]{5}{*}{1} & HITACHI EX100-5 PC100 Type 14 & 1 Unit & $1 / 1 / 2011$ & $26 / 6 / 2011$ & $\mathrm{Rp}$ & $1,200,000,000$ & $\mathrm{Rp}$ & $500,000,000$ & $20 \%$ & $\mathrm{Rp}$ & $70,000,000$ & $\mathrm{Rp}$ & $1,130,000,000$ \\
\hline & & & & & & & & & & $\operatorname{Rp}$ & $140,000,000$ & $\mathrm{Rp}$ & $990,000,000$ \\
\hline & & & & & & & & & & $\operatorname{Rp}$ & $140,000,000$ & $\mathrm{Rp}$ & $850,000,000$ \\
\hline & & & & & & & & & & $\operatorname{Rp}$ & $140,000,000$ & $\mathrm{Rp}$ & $710,000,000$ \\
\hline & & & & & & & & & & $\mathrm{Rp}$ & $140,000,000$ & $R p$ & $570,000,000$ \\
\hline \multirow[t]{5}{*}{2} & HITACHI EX100-5 PC100 Type 12 & 1 Unit & $26 / 1 / 2011$ & $26 / 6 / 2011$ & $\mathrm{RP}$ & $425,000,000$ & $R p$ & $100,000,000$ & $20 \%$ & $R p$ & $32,500,000$ & $\mathrm{Rp}$ & $392,500,000$ \\
\hline & & & & & & & & & & $\operatorname{Rp}$ & $65,000,000$ & $\mathrm{Rp}$ & $327,500,000$ \\
\hline & & & & & & & & & & $\mathrm{Rp}$ & $65,000,000$ & $\mathrm{Rp}$ & $262,500,000$ \\
\hline & & & & & & & & & & $\operatorname{Rp}$ & $65,000,000$ & $\mathrm{Rp}$ & $197,500,000$ \\
\hline & & & & & & & & & & $\mathrm{Rp}$ & $65,000,000$ & $\mathrm{Rp}$ & $132,500,000$ \\
\hline \multirow[t]{5}{*}{3} & MITSHUBISHI HINO Type TERONTON & 1 Unit & $1 / 2 / 2011$ & $1 / 3 / 2011$ & Rp & $250,000,000$ & $\mathrm{Rp}$ & $100,000,000$ & $20 \%$ & $\operatorname{Rp}$ & $25,000,000$ & $R p$ & $225,000,000$ \\
\hline & & & & & & & & & & $\mathrm{Rp}$ & $30,000,000$ & $\mathrm{Rp}$ & $195,000,000$ \\
\hline & & & & & & & & & & $\operatorname{Rp}$ & $30,000,000$ & $\mathrm{Rp}$ & $165,000,000$ \\
\hline & & & & & & & & & & $R p$ & $30,000,000$ & $R p$ & $135,000,000$ \\
\hline & & & & & & & & & & $R p$ & $30,000,000$ & $\mathrm{Rp}$ & $105,000,000$ \\
\hline \multirow[t]{7}{*}{4} & MITSHUBISHI HINO Type DUMPTRUCK & 1 Unit & $1 / 2 / 2011$ & $1 / 3 / 2011$ & Rp & $135,000,000$ & $R p$ & $50,000,000$ & $20 \%$ & $R p$ & $14,166,667$ & $R p$ & $120,833,333$ \\
\hline & & & & & & & & & & $R p$ & $17,000,000$ & $\mathrm{Rp}$ & $103,833,333$ \\
\hline & & & & & & & & & & $\mathrm{Rp}$ & $17,000,000$ & $R p$ & $86,833,333$ \\
\hline & & & & & & & & & & $\mathrm{Rp}$ & $17,000,000$ & $\operatorname{Rp}$ & $69,833,333$ \\
\hline & & & & & & & & & & $R p$ & $17,000,000$ & $\mathrm{Rp}$ & $52,833,333$ \\
\hline & & & & & & & & & & & & & \\
\hline & AKTIVA TAHUN 2012 & & & & & & & & & & & & \\
\hline \multirow[t]{5}{*}{1} & HITACHI EX100-5 PC100 Type 12 & 1 Unit & $26 / 5 / 2012$ & $26 / 6 / 2012$ & $\operatorname{Rp}$ & $425,000,000$ & $\mathrm{Rp}$ & $100,000,000$ & $20 \%$ & $\mathrm{Rp}$ & $32,500,000$ & $\mathrm{Rp}$ & $392,500,000$ \\
\hline & & & & & & & & & & $\operatorname{Rp}$ & $65,000,000$ & $\mathrm{Rp}$ & $327,500,000$ \\
\hline & & & & & & & & & & $\mathrm{Rp}$ & $65,000,000$ & $\mathrm{Rp}$ & $262,500,000$ \\
\hline & & & & & & & & & & $R p$ & $65,000,000$ & $R p$ & $197,500,000$ \\
\hline & & & & & & & & & & $\mathrm{Rp}$ & $65,000,000$ & $\mathrm{Rp}$ & $132,500,000$ \\
\hline \multirow[t]{7}{*}{2} & MITSHUBISHI HINO Type DUMPTRUCK & 1 Unit & $1 / 2 / 2012$ & $1 / 3 / 2012$ & $\mathrm{Rp}$ & $135,000,000$ & $\mathrm{Rp}$ & $50,000,000$ & $20 \%$ & $\mathrm{Rp}$ & $14,166,667$ & $R p$ & $120,833,333$ \\
\hline & & & & & & & & & & $\mathrm{Rp}$ & $17,000,000$ & $\mathrm{Rp}$ & $103,833,333$ \\
\hline & & & & & & & & & & $\mathrm{Rp}$ & $17,000,000$ & $\mathrm{Rp}$ & $86,833,333$ \\
\hline & & & & & & & & & & $\operatorname{Rp}$ & $17,000,000$ & $R p$ & $69,833,333$ \\
\hline & & & & & & & & & & $\mathrm{Rp}$ & $17,000,000$ & $\mathrm{Rp}$ & $52,833,333$ \\
\hline & & & & & & & & & & & & & \\
\hline & AKTIVA TAHUN 2012 & & & & & & & & & & & & \\
\hline \multirow[t]{5}{*}{1} & HITACHI EX100-5 PC100 Type 12 & 1 Unit & $26 / 5 / 2013$ & $26 / 6 / 2013$ & Rp & $425,000,000$ & $R p$ & $100,000,000$ & $20 \%$ & $R p$ & $32,500,000$ & $R p$ & $392,500,000$ \\
\hline & & & & & & & & & & $\operatorname{Rp}$ & $65,000,000$ & $\mathrm{Rp}$ & $327,500,000$ \\
\hline & & & & & & & & & & $R p$ & $65,000,000$ & $\mathrm{Rp}$ & $262,500,000$ \\
\hline & & & & & & & & & & $\mathrm{Rp}$ & $65,000,000$ & $\mathrm{Rp}$ & $197,500,000$ \\
\hline & & & & & & & & & & $\operatorname{Rp}$ & $65,000,000$ & $R p$ & $132,500,000$ \\
\hline \multirow[t]{5}{*}{2} & MITSHUBISHI HINO Type DUMPTRUCK & 2 Unit & $1 / 2 / 2013$ & $1 / 3 / 2013$ & $\operatorname{Rp}$ & $135,000,000$ & $\mathrm{Rp}$ & $50,000,000$ & $20 \%$ & $\operatorname{Rp}$ & $14,166,667$ & $\mathrm{Rp}$ & $120,833,333$ \\
\hline & & & & & & & & & & $R p$ & $17,000,000$ & $\mathrm{Rp}$ & $103,833,333$ \\
\hline & & & & & & & & & & $R p$ & $17,000,000$ & $R p$ & $86,833,333$ \\
\hline & & & & & & & & & & $\mathrm{Rp}$ & $17,000,000$ & $R p$ & $69,833,333$ \\
\hline & & & & & & & & & & $R p$ & $17,000,000$ & $R p$ & $52,833,333$ \\
\hline
\end{tabular}




\subsection{Metode Saldo Menurun (Double Declining Balance Method):}

\begin{tabular}{|c|c|c|c|c|c|c|c|c|c|c|c|}
\hline \multicolumn{12}{|c|}{$\begin{array}{l}\text { DAFTAR AKTIVA OPERASIONAL YANG MASIH BERFUNGSI } \\
\text { MILIK PT. DELIMAS LESTARI JAYA } \\
\text { METODE SALDO MENURUN }\end{array}$} \\
\hline \multirow[t]{2}{*}{ No } & Nama Aktiva & Quantity & Tgl Pembelian & TgI Mulai & Jumlah & Penyusutar & Tarif & \multicolumn{2}{|r|}{ Akum Penyu } & \multicolumn{2}{|c|}{ Nilai Buku } \\
\hline & Kendaraan dan Alat Berat Tahun 2011 & & /Pemakaian & Disusut & Biaya Perolehan & Pertahun & Saldo Menurun & & Thn ini & & Tahun ini \\
\hline \multirow[t]{5}{*}{1} & HITACHI EX100-5 PC100 Type 14 & 1 Unit & $1 / 1 / 2011$ & $26 / 6 / 2011$ & $\operatorname{Rp~} 1,200,000,000$ & $20 \%$ & $40 \%$ & $\mathrm{Rp}$ & $240,000,000$ & $\mathrm{Rp}$ & $960,000,000$ \\
\hline & & & & & & & & $\mathrm{Rp}$ & $384,000,000$ & $\mathrm{Rp}$ & $576,000,000$ \\
\hline & & & & & & & & $\mathrm{Rp}$ & $230,400,000$ & $R p$ & $345,600,000$ \\
\hline & & & & & & & & $\mathrm{Rp}$ & $138,240,000$ & $\mathrm{Rp}$ & $207,360,000$ \\
\hline & & & & & & & & $\mathrm{Rp}$ & $82,944,000$ & $\mathrm{Rp}$ & $124,416,000$ \\
\hline \multirow[t]{5}{*}{2} & HITACHI EX100-5 PC100 Type 12 & 1 Unit & $26 / 1 / 2011$ & $26 / 6 / 2011$ & Rp $425,000,000$ & $20 \%$ & $40 \%$ & $\mathrm{Rp}$ & $85,000,000$ & $\operatorname{Rp}$ & $340,000,000$ \\
\hline & & & & & & & & & $136,000,000$ & $\mathrm{Rp}$ & $289,000,000$ \\
\hline & & & & & & & & & $81,600,000$ & $\mathrm{Rp}$ & $343,400,000$ \\
\hline & & & & & & & & $\mathrm{Rp}$ & $48,960,000$ & $\mathrm{Rp}$ & $376,040,000$ \\
\hline & & & & & & & & $\mathrm{Rp}$ & $29,376,000$ & $\mathrm{Rp}$ & $395,624,000$ \\
\hline \multirow[t]{5}{*}{3} & MITSHUBISHI HINO Type TERONTON & 1 Unit & $1 / 2 / 2011$ & $1 / 3 / 2011$ & $\operatorname{Rp} 250,000,000$ & $20 \%$ & $40 \%$ & $\mathrm{Rp}$ & $83,333,333$ & $\mathrm{Rp}$ & $166,666,667$ \\
\hline & & & & & & & & $\mathrm{Rp}$ & $66,666,667$ & $\mathrm{Rp}$ & $183,333,333$ \\
\hline & & & & & & & & $\mathrm{Rp}$ & $40,000,000$ & $\mathrm{Rp}$ & $210,000,000$ \\
\hline & & & & & & & & $\mathrm{Rp}$ & $24,000,000$ & $\mathrm{Rp}$ & $226,000,000$ \\
\hline & & & & & & & & $\mathrm{Rp}$ & $14,400,000$ & $\mathrm{Rp}$ & $235,600,000$ \\
\hline \multirow[t]{6}{*}{4} & MITSHUBISHI HINO Type DUMPTRUCK & 1 Unit & $1 / 2 / 2011$ & $1 / 3 / 2011$ & Rp $135,000,000$ & $20 \%$ & $40 \%$ & $\mathrm{Rp}$ & $45,000,000$ & $\mathrm{Rp}$ & $90,000,000$ \\
\hline & & & & & & & & $\mathrm{Rp}$ & $36,000,000$ & $\mathrm{Rp}$ & $99,000,000$ \\
\hline & & & & & & & & $\mathrm{Rp}$ & $21,600,000$ & $\mathrm{Rp}$ & $113,400,000$ \\
\hline & & & & & & & & $\mathrm{Rp}$ & $12,960,000$ & $\mathrm{Rp}$ & $122,040,000$ \\
\hline & & & & & & & & $\mathrm{Rp}$ & $7,776,000$ & $\mathrm{Rp}$ & $127,224,000$ \\
\hline & AKTIVA TAHUN 2012 & & & & & & & & & & \\
\hline \multirow[t]{5}{*}{1} & HITACHI EX100-5 PC100 Type 12 & 1 Unit & $26 / 1 / 2012$ & $26 / 6 / 2012$ & Rp $425,000,000$ & $20 \%$ & $40 \%$ & $\mathrm{Rp}$ & $85,000,000$ & $\mathrm{Rp}$ & $340,000,000$ \\
\hline & & & & & & & & & $136,000,000$ & $\mathrm{Rp}$ & $289,000,000$ \\
\hline & & & & & & & & & $81,600,000$ & $\operatorname{Rp}$ & $343,400,000$ \\
\hline & & & & & & & & $\mathrm{Rp}$ & $48,960,000$ & $\mathrm{Rp}$ & $376,040,000$ \\
\hline & & & & & & & & & $29,376,000$ & $\operatorname{Rp}$ & $395,624,000$ \\
\hline \multirow[t]{6}{*}{2} & MITSHUBISHI HINO Type DUMPTRUCK & 1 Unit & $1 / 2 / 2012$ & $1 / 3 / 2012$ & Rp $\quad 135,000,000$ & $20 \%$ & $40 \%$ & $\mathrm{Rp}$ & $45,000,000$ & $\mathrm{Rp}$ & $90,000,000$ \\
\hline & & & & & & & & $\mathrm{Rp}$ & $36,000,000$ & $\operatorname{Rp}$ & $99,000,000$ \\
\hline & & & & & & & & $\mathrm{Rp}$ & $21,600,000$ & $\mathrm{Rp}$ & $113,400,000$ \\
\hline & & & & & & & & $\mathrm{Rp}$ & $12,960,000$ & $\operatorname{Rp}$ & $122,040,000$ \\
\hline & & & & & & & & $\mathrm{Rp}$ & $7,776,000$ & $\mathrm{Rp}$ & $127,224,000$ \\
\hline & AKTIVA TAHUN 2013 & & & & & & & & & & \\
\hline \multirow[t]{5}{*}{1} & HITACHI EX100-5 PC100 Type 12 & 1 Unit & $26 / 5 / 2013$ & $26 / 6 / 2013$ & Rp $\quad 425,000,000$ & $20 \%$ & $40 \%$ & $\mathrm{Rp}$ & $85,000,000$ & $\mathrm{Rp}$ & $340,000,000$ \\
\hline & & & & & & & & & $136,000,000$ & $\operatorname{Rp}$ & $289,000,000$ \\
\hline & & & & & & & & & $81,600,000$ & $\mathrm{Rp}$ & $343,400,000$ \\
\hline & & & & & & & & $\mathrm{Rp}$ & $48,960,000$ & $\operatorname{Rp}$ & $376,040,000$ \\
\hline & & & & & & & & $\mathrm{Rp}$ & $29,376,000$ & $\mathrm{Rp}$ & $395,624,000$ \\
\hline \multirow[t]{5}{*}{2} & MITSHUBISHI HINO Type DUMPTRUCK & 2 Unit & $1 / 2 / 2013$ & $1 / 3 / 2013$ & Rp $135,000,000$ & $20 \%$ & $40 \%$ & $\mathrm{Rp}$ & $45,000,000$ & $\mathrm{Rp}$ & $90,000,000$ \\
\hline & & & & & & & & $\mathrm{Rp}$ & $36,000,000$ & $\mathrm{Rp}$ & $99,000,000$ \\
\hline & & & & & & & & $\mathrm{Rp}$ & $21,600,000$ & $\operatorname{Rp}$ & $113,400,000$ \\
\hline & & & & & & & & $\operatorname{Rp}$ & $12,960,000$ & $\mathrm{Rp}$ & $122,040,000$ \\
\hline & & & & & & & & $\mathrm{Rp}$ & $7,776,000$ & $\operatorname{Rp}$ & $127,224,000$ \\
\hline
\end{tabular}




\subsection{Analisa Perbandingan Penyusutan Aktiva Tetap}

Perusahaan menggunakan metode garis lurus dalam penyusunan laporan keuangan untuk memaksimumkan laba bersih. Pada saat yang sama, perusahaan menggunakan metode saldo menurun ganda dalam menghitung pajak penghasilan untuk meminimkan pajak penghasilan. Metode ini sejalan dengan prinsip pengakuan beban, karena beban depresiasi yang tinggi pada tahun-tahun awal sejalan dengan pendapatan yang tinggi pula di tahun-tahun awal mengingat aset masih baru.Hal ini juga sejalan dengan beban depresiasi yang lebih kecil di tahun-tahun berikutnya ketika aktiva sudah semakin tua dan menghasilkan pendapatan yang lebih rendah, selain itu aktiva-aktiva tertentu kemanfaatannya cepat sekali menurun.

\subsection{Perlakuan Aktiva Tetap Setelah Disusutkan}

Perlakuan aktiva tetap setelah disusutkan oleh PT. Delimas Lestari Jaya dilakukan sesuai dengan kebijakan perusahaan. Yaitu dengan cara sebagai berikut:

a. HITACHI EX-100-5 PC100 Type 14, karena masih digunakan oleh PT. Delimas Lestari Jaya aktiva ini tetap melakukan pemeliharaan (maintanance) dilakukan dengan cara pengecekan mesin dan perawatan lainnya seperti pemberian solar dapat dipergunakan dengan baik.

b. HITACHI EX-100-5 PC100 Type 12, karena masih digunakan oleh PT. Delimas Lestari Jaya aktiva ini tetap melakukan pemeliharaan (maintanance) dilakukan dengan cara pengecekan mesin dan perawatan perawatan lainnya seperti pemberian solar dapat dipergunakan dengan baik.

c. MITSHUBISI HINO Type Tronton, aktiva ini tetap digunakan oleh PT. Delimas Lestari Jaya dengan cara reparasi (repair) untuk memperbaikikeadaan aktiva menjadi baik setelah mengalami kerusakan sebagian atau seluruhnya dengan cara pengecekan mesin dan penggantian oli agar dapat dipergunakan dan dapat menjelaskan fungsinya kembal

d. MITSHUBISI HINO Type DumpTruck, aktiva ini tetap di gunakan oleh PT. Delimas Lestari Jaya dengan cara reparasi (repair) untuk memperbaikikeadaan aktiva menjadi baik setelah mengalami kerusakan sebagian atau seluruhnya, seluruhnya dengan cara pengecekan mesin dan penggantian oli agar dapat dipergunakan dan dapat menjelaskan fungsinya kembali.

\section{KESIMPULAN}

PT. Delimas Lestari Jaya menggunakan penyusutan garis lurus terhadap ke empat aktiva yang dimilikinya. Menurut PT. Delimas Lestari Jaya penggunaan metode garis lurus digunakan karena metode ini menggunakan perhitungan yang mudah dan cepat untuk dilakukan. Penulis mencoba menggunakan metode saldo menurun sebagai perbandingan terhadap metode yang telah digunakan PT. Delimas Lestari Jaya. Metode saldo menurun lebih baik bila digunakan untuk perusahaan yang memiliki aktiva tetap dengan nilai perolehan yang cukup besar, karena dari hasil perhitungannya aktiva tersebut biasanya efektif dan maksimal digunakan di tahun-tahun awal, sehingga apabila kondisi aktiva tetap tersebut menurun bisa diambil tindakan yang tepat untuk memperbaikinya.

\section{SARAN}

Penulis menyarankan agar dapat dilakukan penelitian lanjutan dengan membangun sebuah aplikasi berbasis web. 


\section{DAFTAR PUSTAKA}

[1] Baridwan, Zaki. 2010. Intermediated Accounting, Edisi 8 Yogyakarta : BPFE Yogyakarta

[2] Jogiyanto, HM. 2010. Analisis \& Desain Grafis Informasi. Andi Offset : Yogyakarta

[3] Islahuzzaman. 2014. Akuntansi dan Audit. Jakarta : Bumi Aksara

[4] Jusup, Haryono. 2010. Dasar-dasar Akuntansi. Bagian Penerbit Sekolah Tinggi Ilmu Ekonomi YPKN : Yogyakarta

[5] Kieso, dkk. 2013. Akuntansi Intermediate, Edisi 12 Jakarta : Salemba Empat

[6] Nuh, Muhammad. 2012. Intermediate Accounting. Fajar : Jakarta

[7] Sugiarti, Yuni. 2011. Metode Penelitian. Dinas Pendidikan Provinsi Banten :Banten.

[8] Widyanto, Ardes. 2014. Pemrograman Dasar. Jakarta : Yudhistira

[9] Lestari, Rizky. 2018. Perhitungan Penyusutan Aset Tetap Dengan Menggunakan Metode Saldo Menurun Ganda (Double Declining Method) Di Dinas Perhubungan Kabupaten Bandung.Diploma thesis, UIN Sunan Gunung Djati Bandung.

[10] Jayanti, Putri Okta Dwi. 2018. ANALISIS PENERAPAN METODE PENYUSUTAN AKTIVA TETAP DAN IMPLIKASINYA TERHADAP LABA PERUSAHAAN (STUDI KASUS PADA PT.DAGO ENDAH TAHUN 2012-2016). Skripsi thesis, Universitas Mercu Buana Yogyakarta.

[11] Adelia, Dhea. 2018. ANALISIS PERBANDINGAN HARGA POKOK PRODUKSI KAIN TENUN SONGKET PADA PENGRAJIN SONGKET VR TEXTILE DAN HJ. ASMI ASTARI SONGKET. Other thesis, POLITEKNIK NEGERI SRIWIJAYA.

[12] Linda Arisanty Razak, ddk. 2019. Analisis Perhitungan Penyusutan Aset Tetap Menurut Standar Akuntansi Keuangan Dan Peraturan Perpajakan Pada PT. Gowa Makassar Tourism Tbk. Vol 4 No 1. TANGIBLE JOURNAL.

[13] Andini Nazar Pratiwi, dkk. 2019. PENGARUH BOOK-TAX DI FFERENCES, LEVERAGE, DAN UKURAN PERUSAHAAN TERHADAP PERSISTENSI LABA (Studi Pada Perusahaan Properti dan Real Estae yang Terdaftar di Bursa Efek Indonesia Tahun 2013-2017). Skripsi(S1) thesis, Perpustakaan FEB Unpas.

[14] Wida Khusnul Khotimah dkk. 2019. Aplikasi Penyusutan Aset Tetap Serta Pembebanan Biaya Reparasi Dan Pemeliharaan. Vol 5, No 3. eProceedings of Applied Science. 